\title{
Pengendalian Jadwal Proyek Isolasi Boiler Dengan Metode Time Cost Trade Off Di PT Athirah Gemilang Mandiri
}

\author{
R. Lestari
}

\begin{abstract}
Abstrak-PT Athirah Gemilang Mandiri merupakan perusahaan yang bergerak dibidang kontraktor dan supplier. Proyek yang sedang dijalankan yaitu proyek isolasi boiler dimana mengalami keterlambatan dalam penyelesaian proyek. Penelitian ini bertujuan untuk mengetahui total waktu serta biaya optimal yang harus di keluarkan setelah pelaksanaan proyek dipercepat supaya dapat mengatasi keterlambatan yang terjadi serta memberikan solusi mengenai biaya yang harus dikeluarkan agar lebih efisien.Untuk menyelesaikan permasalahan dalam penjadwalan proyek penelitan ini menggunakan metode Critical Path Method dan Time Cost Trade Off. Critical Path Method merupakan metode yang berorientasi pada waktu, metode ini mengidentifikasi jalur kritis pada aktifitas yang ditentukan ketergantungan antar aktifitasnya. Sedangkan Time Cost Trade Off merupakan metode pertukaran waktu dan biaya dimana memberikan alternatif kepada perencana proyek untuk menyusun perencanaan yang terbaik sehingga mengoptimalkan waktu dan biaya dalam menyelesaikan proyek. Dari hasil perhitungan maka dapat ditarik kesimpulan bahwa total waktu optimal setelah pelaksanaan proyek dipercepat yaitu 44 hari dari durasi waktu normal 48 hari maka diperlukan percepatan waktu selama 4 hari agar selesai sesuai target utama. Selanjutnya biaya optimal setelah dipercepat sebesar Rp.643.249.048 dari biaya normal sebesar Rp.642.171.700 jadi terjadi penambahan biaya setelah dipercepat sebesar Rp.1.107.348.
\end{abstract}

Kata Kunci-Penjadwalan Proyek, Time Cost Trade Off, Primavera Project Planner

Abstract - PT Athirah Gemilang Mandiri is a company engaged in contractors and suppliers. The ongoing project is a boiler insulation project which is experiencing delays in project completion. This study aims to determine the total time and optimal costs that must be spent after project implementation is accelerated in order to overcome the delays that occur and provide solutions regarding costs that must be spent to be more efficient. To solve problems in scheduling this research project using the Critical Path Method and Time Cost Trade Off. Critical Path Method is a time-oriented method, this method identifies critical paths in activities that are determined by the dependency between activities. Whereas Time Cost Trade Off is a method of exchanging time and costs which provides an alternative to the project planner to arrange the best plan so as to optimize the time and cost of completing the project. From the calculation results, it can be concluded that the optimal total time after project implementation is accelerated, which is 44 days from the normal 48 day duration, so we need to accelerate the time for 4 days to complete the main target. Furthermore, the optimal cost after being accelerated is Rp.643,249,048 from the normal cost of Rp.642.171.700 so there is an additional cost after accelerating Rp.1.107.348.

Keywords_Project Scheduling, Time Cost Trade Off, Critical Path Method, Primavera Project Planner

\section{PENDAHULUAN}

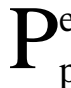
enjadwalan proyek merupakan perhitungan dalam pengalokasian waktu terhadap masing-masing kegiatan pelaksanaan suatu proyek yang sedemikian rupa sehingga tercapai hasil yang optimal. Penjadwalan meliputi waktu, tenaga kerja, material, peralatan dan keuangan. Penjadwalan proyek dikatakan baik apabila dapat mengurangi keterlambatan, pembengkakan biaya serta perselisihan-perselisihan kontraktual.

PT.Athirah Gemilang Mandiri merupakan perusahaan yang bergerak di bidang supplier dan kontraktor. Perusahaan dapat menyediakan material insulation dan refractory serta jasa pemasangan atau instalasi perbaikan boiler dan peralatan industri yang berhubungan dengan panas. Pada jasa pemasangan atau perbaikan boiler yang sedang di kerjakan oleh kontraktor dan setelah selesai di kerjakan akan di inspeksi kembali dan ketika terdapat pipa yang masih rusak maka dilakukan pembongkaran dan pemasangan yang baru oleh kontraktor tersebut. Hal ini menyebabkan permasalahan muncul karena proyek perbaikan isolasi bisa di lanjutkan kembali ketika penggantian dari kerusakan tersebut selesai di kerjakan.

Tujuan dilakukannya penelitian ini yaitu untuk mengetahui total waktu optimal setelah pelaksanaan proyek dipercepat dan untuk mengetahui total biaya optimal yang harus dikeluarkan setelah pelaksanaan proyek dipercepat. 


\section{METODE DAN PROSEDUR}

Metode yang digunakan dalam penelitian ini yaitu metode Time Cost Trade Off (TCTO) dan penerapan Primavera 6.0. Metode untuk mempercepat atau mengkompres durasi proyek salah satunya adalah TCTO (Time Cost Trade Off) atau biasa disebut metode pertukaran waktu dan biaya. Perhitungan dalam proses percepatan ini hanya dilakukan pada aktivitas-aktivitas yang berada pada lintasan kritis dengan maksud agar dicapai pengurangan waktu proyek sebesar-besarnya dengan pengeluaran biaya yang sekecil-kecilnya. Dalam hal ini ada beberapa cara yang dapat dilakukan untuk mempercepat durasi total proyek, yaitu dengan penambahan jumlah jam kerja, penambahan tenaga kerja, penambahan peralatan, pemilihan sumber daya manusia yang berkualitas, dan penggunaan metode konstruksi yang efektif.

Metode untuk mengidentifikasi lintasan kritis yaitu Critical Path Method (CPM), CPM merupakan suatu metode yang menggunakan arrow diagram dalam menentukan lintasan kritis. Lintasan kritis yaitu lintasan kegiatan yang tidak boleh terlambat ataupun mengalami penundaan pelaksanaan proyek. Selain itu, di dalam CPM mengenal adanya istilah ES (Earliest activity start time) yaitu waktu mulai paling awal suatu kegiatan, EF (Earliest activity finish time) yaitu waktu selesai paling awal suatu kegiatan, LS (Latest activity start time) yaitu waktu paling lambat kegiatan boleh dimulai tanpa memperlambat proyek secara keseluruhan, sedangkan LF (Latest activity finish time) yaitu waktu paling lambat kegiatan diselesaikan tanpa memperlambat penyelesaian proyek.

Primavera adalah aplikasi project manajemen yang memiliki kemampuan memadai serta diakui dan dipergunakan secara luas untuk membantu para project manager. Primavera 6.0 adalah program untuk perencanaan dan pengawasan proyek tingkat tinggi. Memberikan perencanaan proyek, sumber daya, daftar kontrol biaya proyek secara luas.

\section{A. Teknik Analisis Data}

Metode Time Cost Trade Off (TCTO)

Berikut ini langkah-langkah dalam pengolahan data menggunakan metode Time Cost Trade Off :

a. Crash Duration

Crash duration merupakan durasi kegiatan pada proyek yang telah dipercepat.
Berikut langkah-langkah dalam menghitung

Crash duration adalah sebagai berikut :

\section{Menghitung Produktivitas Harian}

$$
\text { Produktivi tas Harian }=\frac{\text { Volume harian }}{\text { Durasi normal }}
$$

\section{Menghitung Produktivitas Per Jam}

Produktivi tas Per jam $=\frac{\text { Produktivi tas harian }}{\text { Jam kerja normal harian }}$

\section{Menghitung Produktivitas Lembur \\ Produktivitas lembur $=$ jam kerja lembur $\mathrm{x}$ koef.produktifitas x prod. perjam}

\section{Menghitung Produktivitas Harian Setelah Crash \\ Produktifitas harian setelah crash $=$ prod. harian + prod. lembur}

\section{Menghitung Crash Duration}

$$
\text { Crash Duration }=\frac{\text { Volume Pekerjaan }}{\text { Prod harian setelah } \text { crash }}
$$

b. Crash Cost

Crash cost merupakan biaya yang diperlukan akibat dari penyelesaian kegiatan dengan durasi yang telah dipercepat. Berikut langkah-langkah yang dapat menghitung Crash cost adalah sebagai berikut :

\section{Menghitung Upah Kerja Harian Normal} prod harian $x$ harga satuan upah kerja

\section{Menghitung Upah Kerja Perjam Normal Prod perjam $x$ harga satuan upah kerja}

\section{Menghitung Upah Kerja Lembur Per Hari} $1,5 \mathrm{x}$ upah sejam normal $+2 n \mathrm{x}$ upah sejam normal

\section{Menghitung Crash Cost Tenaga Kerja Per Hari \\ upah harian + upah kerja lembur per hari}

\section{Menghitung Crash Cost Total \\ crash cost per hari $\mathrm{x}$ crash duration}

\section{c. Cost Slope}

Cost slope merupakan pertambahan biaya langsung (direct cost) untuk mempercepat suatu aktivitas per satuan 
waktu. Berikut rumus dalam menghitung cost slope adalah sebagai berikut :

$$
\text { Cost Slope }=\frac{\text { crash cost }- \text { normal cost }}{\text { normal duration }- \text { crash duration }}
$$

B. Pengumpulan Data

\section{Data Uraian Pekerjaan dan Durasi Proyek}

Pada perencanaan proyek dimulai dengan menguraikan proyek menjadi beberapa kegiatan atau aktivitas-aktivitas. Data ini terdiri dari jenis pekerjaan, kode kegiatan dan waktu pelaksanaan proyek untuk mengontrol setiap item pekerjaan yang dilaksanakan di

satuan waktu yang telah di tentukan. Kegiatan proyek pada PT Athirah Gemilang Mandiri seperti pada tabel di bawah ini :

Tabel 1

Data Uraian Pekerjaan Dan Durasi Proyek

\begin{tabular}{rlcc}
\hline No & \multicolumn{1}{c}{ Jenis Pekerjaan } & $\begin{array}{c}\text { Kode } \\
\text { Kegiatan }\end{array}$ & $\begin{array}{c}\text { Waktu } \\
\text { (Hari) }\end{array}$ \\
\hline 1 & Pekerjaan Proses Pendinginan & $\mathrm{A}$ & 2 \\
2 & Pekerjaan membuka lubang masuk & $\mathrm{B}$ & 1 \\
3 & Pekerjaan membula penutup lubang & $\mathrm{C}$ & 1 \\
4 & Pekerjaan pembersihan pasir & $\mathrm{D}$ & 2 \\
5 & Pekerjaan membuat perancah tungku & $\mathrm{E}$ & 4 \\
6 & Pekerjaan membuat perancah separator & $\mathrm{F}$ & 4 \\
7 & Pekerjaan pemeriksaan ketebalan ultrasonik & $\mathrm{G}$ & 5 \\
8 & Pekerjaan memasang CO katup & $\mathrm{H}$ & 3 \\
9 & Pekerjaan memasang sisipan lempeng & $\mathrm{I}$ & 2 \\
10 & Pekerjaan pemeriksaan kebocoran & $\mathrm{J}$ & 5 \\
11 & Pekerjaan tutupjaringan listrik & $\mathrm{K}$ & 3 \\
12 & Pekerjaan memperbaiki pipa tungku panel & $\mathrm{L}$ & 14 \\
13 & Pemberian sertifikat boiler oleh Wismar & $\mathrm{M}$ & 2 \\
14 & Pekerjaann membongkar perancah tungku & $\mathrm{N}$ & 3 \\
15 & Pekerjaan membongkar perancah separator & $\mathrm{O}$ & 3 \\
16 & Pekerjaan menutup tutup lubang & $\mathrm{P}$ & 1 \\
17 & Pekerjaan menutup tungku & $\mathrm{Q}$ & 1 \\
\hline
\end{tabular}

\section{Pengalokasian Tenaga Kerja}

Pengalokasian kebutuhan tenaga kerja untuk setiap aktivitas atau kegiatan proyek pada PT Athirah Gemilang Mandiri sudah ditentukan diawal perencanaan proyek sebelum proyek dilaksanakan. Alokasi tenaga kerja pada proyek isolasi boiler dapat dilihat pada tabel berikut ini :

Tabel 2

Alokasi Manpower Proyek

\begin{tabular}{|c|c|c|c|c|c|}
\hline Jenis Pekerjaan & $\begin{array}{c}\text { Waktu } \\
\text { Perencanaan }\end{array}$ & $\begin{array}{l}\text { Waktu } \\
\text { Aaktual } \mathrm{F}\end{array}$ & oreman & $\begin{array}{c}\text { Skill } \\
\text { n }\end{array}$ & Helper \\
\hline & (hari) & & & & \\
\hline 1 Pekerjaan Proses Pendinginan & 2 & 2 & & 2 & 2 \\
\hline 2 Pekerjaan membuka lubang masuk & 1 & 1 & & 1 & \\
\hline 3 Pekerjaan membuka penutup lubang & 2 & 2 & & 2 & 1 \\
\hline 4 Pekerjaan pembersihan pasir & 2 & 2 & & 2 & 2 \\
\hline 5 Pekerjaan membuat perancalh tungku & 4 & 4 & & 2 & 2 \\
\hline 6. Pekerjaan membuat perancal separator & 4 & 4 & & 2 & 2 \\
\hline $\begin{array}{l}7 \text { Pekerjaan pemeriksaan ketebalan } \\
\text { ultrasonik }\end{array}$ & n & 5 & & 3 & \\
\hline \& Pekerjaan memasang CO katup & 3 & 3 & & 2 & 2 \\
\hline 9 Pekerjaan memasang sisipan lempeng & 2 & 2 & 1 & 2 & 2 \\
\hline 10 Pekerjaan pemeriksaan kebocoran & 5 & 5 & & 3 & 3 \\
\hline 11 Pekerjaan tutup jaringan listrik & 3 & 3 & & 2 & \\
\hline 12 Pekerjaan memperbaiki pipa tungku panel & 11 & 14 & & 3 & 3 \\
\hline 13 Pemberian settifikat boiler oleh Wismar & 2 & 2 & & 2 & \\
\hline 14 Pekerjaan membongkar perancah tungku & 3 & 3 & & 2 & 2 \\
\hline 15 Pekejjaan membongkar perancah & h & 3 & & 2 & 2 \\
\hline 16 Pekerjaan menutup tutup lubang & 1 & 1 & & 1 & 1 \\
\hline 17 Pekerjaan menutup tungku & 1 & 1 & & 1 & 1 \\
\hline
\end{tabular}

III. HASIL

\section{Critical Path Method (CPM)}

Berdasarkan hasil pengumpulan data maka dapat dilakukan perhitungan untuk mengetahui aktivitasaktivitas yang berada di lintasan kritis.

Jalur kritis adalah lintasan sepanjang diagram jaringan yang mempunyai waktu terpanjang (durasi proyek) untuk mengetahui dengan cepat kegiatankegiatan yang tingkat kepekaan tinggi terhadap keterlamatan pelaksanaan penyelenggara proyek apabila kegiatan tersebut terlambat. Dalam menentukan lintasan kritis dihitung dengan perhitungan maju dan perhitungan mundur.

Tabel 3

Perhitungan Maju

\begin{tabular}{|c|c|c|c|c|}
\hline \multirow{2}{*}{ Jenis Pekerjaan } & \multirow{2}{*}{$\begin{array}{l}\text { Kode } \\
\text { Kegiatan }\end{array}$} & \multirow{2}{*}{$\begin{array}{l}\text { Waktu } \\
\text { (Hari) }\end{array}$} & \multicolumn{2}{|c|}{ Perhitungan Maju } \\
\hline & & & ES & $\mathrm{EF}$ \\
\hline 1 Pekerjaan Proses Pendinginan & A & 2 & 0 & 2 \\
\hline 2 Pekerjaan membuka lubang masuk & B & 1 & 2 & 3 \\
\hline 3 Pekerjaan membuka penutup lubang & $\mathrm{C}$ & 2 & 2 & 4 \\
\hline 4 Pekerjaan pembersihan pasir & D & 2 & 2 & 4 \\
\hline 5 Pekerjaan membuat perancah tungku & E & 4 & 4 & 8 \\
\hline 6 Pekerjaan membuat perancah separator & F & 4 & 8 & 12 \\
\hline 7 Pekerjaan pemeriksaan ketebalan ultrasonik & G & 5 & 12 & 17 \\
\hline 8 Pekerjaan memasang $\mathrm{CO}$ katup & $\mathrm{H}$ & 3 & 12 & 15 \\
\hline 9 Pekerjaan memasang sisipan lempeng & I & 2 & 17 & 19 \\
\hline 10 Pekerjaan pemeriksaan kebocoran & $\mathrm{J}$ & 5 & 19 & 24 \\
\hline 11 Pekerjaan tutup jaringan listrik & $\mathrm{K}$ & 3 & 19 & 22 \\
\hline 12 Pekerjaan memperbaiki pipa tungku panel & $\mathrm{L}$ & 14 & 24 & 38 \\
\hline 13 Pemberian sertifikat boiler oleh Wismar & M & 2 & 38 & 40 \\
\hline 14 Pekerjaan membongkar perancah tungku & $\mathrm{N}$ & 3 & 40 & 43 \\
\hline 15 Pekerjaan membongkar perancah separator & 0 & 3 & 43 & 46 \\
\hline 16 Pekerjaan menutup tutup lubang & $\mathrm{P}$ & 1 & 46 & 47 \\
\hline 17 Pekerjaan menutup tungku & Q & 1 & 47 & 48 \\
\hline
\end{tabular}

Tabel 4

Perhitungan Mundur

\begin{tabular}{|c|c|c|c|c|}
\hline \multirow[t]{2}{*}{ Jenis Pekerjaan } & \multirow{2}{*}{$\begin{array}{l}\text { Kode } \\
\text { Kegiatan }\end{array}$} & \multirow{2}{*}{$\begin{array}{l}\text { Waktu } \\
\text { (Hari) }\end{array}$} & \multicolumn{2}{|c|}{$\begin{array}{l}\text { Perhitungar } \\
\text { Mundur }\end{array}$} \\
\hline & & & LS & LF \\
\hline I Pekerjaan Proses Pendinginan & A & 2 & 0 & 2 \\
\hline 2 Pekerjaan membuka lubang masuk & B & 1 & 2 & 4 \\
\hline 3 Pekerjaan membuka penutup lubang & $\mathrm{C}$ & 2 & 2 & 4 \\
\hline 4 Pekerjaan pembersihan pasir & $\mathrm{D}$ & 2 & 2 & 4 \\
\hline 5 Pekerjaan membuat perancah tungku & E & 4 & 4 & 8 \\
\hline 6 Pekerjaan membuat perancah separator & $\mathrm{F}$ & 4 & 8 & 12 \\
\hline 7 Pekerjaan pemeriksaan ketebalan ultrasonik & G & 5 & 12 & 17 \\
\hline 8 Pekerjaan memasang CO katup & $\mathrm{H}$ & 3 & 12 & 17 \\
\hline 9 Pekerjaan memasang sisipan lempeng & I & 2 & 17 & 19 \\
\hline 10 Pekerjaan pemeriksaan kebocoran & $\mathrm{J}$ & 5 & 19 & 24 \\
\hline 11 Pekerjaan tutup jaringan listrik & $\mathrm{K}$ & 3 & 19 & 24 \\
\hline 12 Pekerjaan memperbaiki pipa tungku panel & L & 14 & 24 & 38 \\
\hline 13 Pemberian sertifikat boiler oleh Wismar & $\mathrm{M}$ & 2 & 38 & 40 \\
\hline 14 Pekerjaan membongkar perancah tungku & $\mathrm{N}$ & 3 & 40 & 43 \\
\hline 15 Pekerjaan membongkar perancah separator & 0 & 3 & 43 & 46 \\
\hline 16 Pekerjaan menutup tutup lubang & $\mathrm{P}$ & 1 & 46 & 47 \\
\hline 17 Pekerjaan menutup tungku & Q & 1 & 47 & 48 \\
\hline
\end{tabular}

Setelah dilakukan perhitungan maju dan mundur maka akan diketahui lintasan kitis. Jalur kritis dapat di tentukan dengan total float sama dengan nol. 
Tabel 5

Perhitungan Total Float

\begin{tabular}{|c|c|c|c|c|c|c|c|}
\hline \multirow[t]{2}{*}{ Jenis Pekerjaan } & \multirow{2}{*}{$\begin{array}{l}\text { Kode } \\
\text { Kegiatan }\end{array}$} & \multirow{2}{*}{$\begin{array}{l}\text { Waktu } \\
\text { (Hari) }\end{array}$} & \multicolumn{4}{|c|}{ Penhitungan Perhitungan } & \multirow{2}{*}{$\begin{array}{l}\text { Float } \\
\text { LS-ES }\end{array}$} \\
\hline & & & ES & $\mathrm{EF}$ & LS & LF & \\
\hline 1 Pekerjaan Proses Pendinginan & A & 2 & 0 & 2 & 0 & 2 & 0 \\
\hline 2 Pekerjaan membuka lubang masuk & B & 1 & 2 & 3 & 3 & 4 & 1 \\
\hline 3 Pekerjaan membuka penutup lubang & $\mathrm{C}$ & 2 & 2 & 4 & 2 & 4 & 0 \\
\hline 4 Pekerjaan pembersihan pasir & D & 2 & 2 & 4 & 2 & 4 & 0 \\
\hline 5 Pekerjaan membuat perancah tungku & E & 4 & 4 & 8 & 4 & 8 & 0 \\
\hline 6 Pekerjaan membuat perancah separator & $\mathrm{F}$ & 4 & 8 & 12 & 8 & 12 & 0 \\
\hline $\begin{array}{l}7 \text { Pekerjaan pemeriksaan ketebalan } \\
\text { ultrasomik }\end{array}$ & G & 5 & 12 & 17 & 12 & 17 & 0 \\
\hline 8 Pekerjaan memasang CO katup & H & 3 & 12 & 15 & 14 & 17 & 2 \\
\hline 9 Pekerjaan memasang sisipan lempeng & I & 2 & 17 & 19 & 17 & 19 & 0 \\
\hline 10 Pekerjaan pemeriksaan kebocoran & $\mathrm{J}$ & 5 & 19 & 24 & 19 & 24 & 0 \\
\hline 11 Pekerjaan tutup jaringan listrik & $\mathrm{K}$ & 3 & 19 & 22 & 21 & 24 & 2 \\
\hline 12 Pekerjaan memperbaiki pipa tungku panel & $\mathrm{L}$ & 14 & 24 & 38 & 24 & 38 & 0 \\
\hline 13 Pemberian sertifikat boiler oleh Wismar & M & 2 & 38 & 40 & 38 & 40 & 0 \\
\hline 14 Pekerjaan membongkar perancah tungku & $\mathrm{N}$ & 3 & 40 & 43 & 40 & 43 & 0 \\
\hline 15 Pekerjaan membongkar perancah separator & 0 & 3 & 43 & 46 & 43 & 46 & 0 \\
\hline 16 Pekerjaan menutup tutup lubang & $\mathrm{P}$ & 1 & 46 & 47 & 46 & 47 & 0 \\
\hline 17 Pekerjaan menutup tungku & Q & 1 & 47 & 48 & 47 & 48 & 0 \\
\hline
\end{tabular}

Setelah melakukan pengolahan data menggunakan Critical Path didapatkan hasil yaitu terdapat 14 Aktivitas yang berada pada jalur kritis diantaranya aktivitas A-C-D-E-F-G-I-J-L-M-N-OP-Q. Berikut gambar 2 di bawah ini menunjukan network diagram lintasan kritis (jalur kritis).

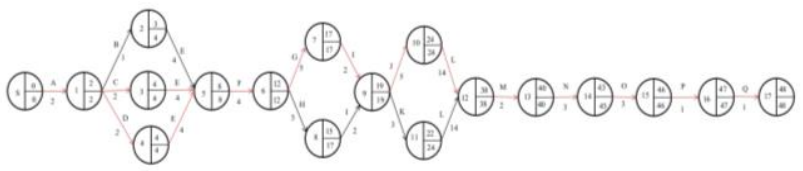

Gambar 2. Network diagram lintasan kritis

\section{Time Cost Trade Off (TCTO)}

Berdasarkan dari hasil pengumpulan data dalam menganalisa waktu serta biaya yang digunakan dalam menyelesaikan pelaksanaan proyek. Setelah itu dilakukan tahap pengolahan data menggunakan Time Cost Trade Off didapatkan hasil perbandingan waktu dan slope biaya normal dengan waktu dan slope biaya dipercepat pada tabel iv di bawah ini :

Tabel 6

\begin{tabular}{|c|c|c|c|c|c|c|c|c|}
\hline \multirow[b]{2}{*}{ Kegiatan } & \multicolumn{3}{|c|}{ Normal } & \multicolumn{3}{|c|}{ Dipercepat } & \multirow{2}{*}{\multicolumn{2}{|c|}{ Slope Biaya/hari }} \\
\hline & $\begin{array}{l}\text { Waktu } \\
\text { (Hari) }\end{array}$ & & Biaya & $\begin{array}{l}\text { Waktu } \\
\text { (Hari) }\end{array}$ & & Biaya & & \\
\hline A & 2 & $\mathrm{Rp}$ & $50,807,200$ & 1 & $\mathrm{Rp}$ & $51,223,771$ & $\mathrm{Rp}$ & 416,571 \\
\hline B & 1 & $\mathrm{Rp}$ & $14,265,300$ & - & $\mathrm{Rp}$ & $14,265,300$ & & - \\
\hline $\mathrm{C}$ & 2 & $\mathrm{Rp}$ & $15,447,000$ & 1 & $\mathrm{Rp}$ & $15,811,571$ & $\mathrm{Rp}$ & 364,571 \\
\hline D & 2 & $\mathrm{Rp}$ & $26,524,200$ & 1 & $\mathrm{Rp}$ & $26,940,771$ & $\mathrm{Rp}$ & 416,571 \\
\hline E & 4 & $\mathrm{Rp}$ & $55,951,000$ & 3 & $\mathrm{Rp}$ & $56,965,000$ & $\mathrm{Rp}$ & $1,014,000$ \\
\hline $\mathrm{F}$ & 4 & $\mathrm{Rp}$ & $43,308,000$ & 3 & $\mathrm{Rp}$ & $44,322,000$ & $\mathrm{Rp}$ & $1,014,000$ \\
\hline G & 5 & $\mathrm{Rp}$ & $66,380,000$ & 4 & $\mathrm{Rp}$ & $68,140,000$ & $\mathrm{Rp}$ & $1,760,000$ \\
\hline $\mathrm{H}$ & 3 & $\mathrm{Rp}$ & $39,708,000$ & - & $\mathrm{Rp}$ & $39,708,000$ & & - \\
\hline I & 2 & $\mathrm{Rp}$ & $51,968,000$ & 1 & $\mathrm{Rp}$ & $52,384,571$ & $\mathrm{Rp}$ & 416,571 \\
\hline $\mathrm{J}$ & 5 & $\mathrm{Rp}$ & $53,408,000$ & 4 & Rp & $55,584,000$ & Rp & $2,176,000$ \\
\hline $\mathrm{K}$ & 3 & $\mathrm{Rp}$ & $39,396,000$ & - & $\mathrm{Rp}$ & $39,396,000$ & & - \\
\hline $\mathrm{L}$ & 14 & $\mathrm{Rp}$ & $74,224,500$ & 10 & $\mathrm{Rp}$ & $75,230,500$ & $\mathrm{Rp}$ & $1,006,000$ \\
\hline M & 2 & $\mathrm{Rp}$ & $14,605,500$ & 1 & $\mathrm{Rp}$ & $14,918,071$ & $\mathrm{Rp}$ & 312,571 \\
\hline $\mathrm{N}$ & 3 & $\mathrm{Rp}$ & $16,820,000$ & 2 & $\mathrm{Rp}$ & $17,264,000$ & $\mathrm{Rp}$ & 444,000 \\
\hline $\mathrm{O}$ & 3 & $\mathrm{Rp}$ & $17,332,000$ & 2 & $\mathrm{Rp}$ & $17,776,000$ & $\mathrm{Rp}$ & 444,000 \\
\hline $\mathrm{P}$ & 1 & $\mathrm{Rp}$ & $13,341,000$ & 1 & $\mathrm{Rp}$ & $14,601,000$ & $\mathrm{Rp}$ & $1,260,000$ \\
\hline $\mathrm{Q}$ & 1 & $\mathrm{Rp}$ & $13,656,000$ & 1 & $\mathrm{Rp}$ & $14,916,000$ & $\mathrm{Rp}$ & $1,260,000$ \\
\hline
\end{tabular}

Setelah itu, tahap selanjutnya dengan menghitung total waktu pelaksanaan proyek masing-masing kegiatan serta menghitung total cost. Berikut uraian kegiatan dengan total waktu serta cost setelah dipercepat :
Tabel 7

Total Waktu Dan Biaya Setelah Dipercepat

\begin{tabular}{|c|c|c|c|}
\hline Kegiatan & Waktu & & otal Biaya \\
\hline Kegiatan Normal & 48 Hari & Rp & $642,141,700$ \\
\hline Kegiatan A (Proses Pendinginan) Dipercepat 1 Hari & 47 Hari & $\mathrm{Rp}$ & $641,829,120$ \\
\hline $\begin{array}{l}\text { Kegiatan C (Membuka Penutup Lubang) Dipercepat } 1 \\
\text { Hari }\end{array}$ & 47 Hari & $\mathrm{Rp}$ & $641,777,120$ \\
\hline Kegiatan D (Pembersihan pasir) Dipercepat 1 Hari & 47 Hari & $\mathrm{Rp}$ & $641,829,120$ \\
\hline $\begin{array}{l}\text { Kegiatan E (Membuat Perancah Tungku) Dipercepat } 1 \\
\text { Hari }\end{array}$ & 47 Hari & $\mathrm{Rp}$ & $642,426,549$ \\
\hline $\begin{array}{l}\text { Kegiatan F (Membuat Perancah Separator) Dipercepat } 1 \\
\text { Hari }\end{array}$ & 47 Hari & $\mathrm{Rp}$ & $642,426,549$ \\
\hline $\begin{array}{l}\text { Kegiatan G (Pemeriksaan Ketebalan Ultrasonik) } \\
\text { Dipercepat } 1 \text { Hari }\end{array}$ & 47 Hari & $\mathrm{Rp}$ & $643,172,549$ \\
\hline $\begin{array}{l}\text { Kegiatan I (Memasang Sisipan Lempeng) Dipercepat } 1 \\
\text { Hari }\end{array}$ & 47 Hari & $\mathrm{Rp}$ & $641,829,120$ \\
\hline Kegiatan J (Pemeriksaan Kebocoran) Dipercepat 1 Hari & 47 Hari & $\mathrm{Rp}$ & $643,588,549$ \\
\hline $\begin{array}{l}\text { Kegiatan L (Memperbaiki Pipa Tungku Panel) } \\
\text { Dipercepat } 4 \text { Hari }\end{array}$ & 44 Hari & $\mathrm{Rp}$ & $643,249,048$ \\
\hline $\begin{array}{l}\text { Kegiatan M (Pemberian Sertifikat Boiler) Dipercepat } 1 \\
\text { Hari }\end{array}$ & 47 Hari & $\mathrm{Rp}$ & $641,725,120$ \\
\hline $\begin{array}{l}\text { Kegiatan N (Membongkar Perancah Tungku) } \\
\text { Dipercepat } 1 \text { Hari }\end{array}$ & 47 Hari & $\mathrm{Rp}$ & $641,856,549$ \\
\hline $\begin{array}{l}\text { Kegiatan O (Membongkar Perancah Separator) } \\
\text { Dipercepat } 1 \text { Hari }\end{array}$ & 47 Hari & $\mathrm{Rp}$ & $641,856,549$ \\
\hline Kegiatan P (Menutup Tutup Lubang) & 48 Hari & $\mathrm{Rp}$ & $642,141,716$ \\
\hline Kegiatan Q (Menutup Tungku) & 48 Hari & $\mathrm{Rp}$ & $642,141,716$ \\
\hline
\end{tabular}

Dari tabel di atas dapat dipilih percepatan kegiatan yang terbaik bagi perusahaan yang tentunya tidak merugikan perusahaan yaitu percepatan kegiatan L yang dipersingkat selama 44 hari, dengan efisiensi waktu proyek 8,33\% dengan total biaya sebesar Rp.643.249.048 sehingga proyek selesai dalam waktu 44 hari.

\section{Primavera Project Planner P6}

Hasil dari penggunaan primavera project planner untuk perkiraan waktu penyelesaian proyek isolasi boiler terdapat pada gambar 2 di bawah ini :

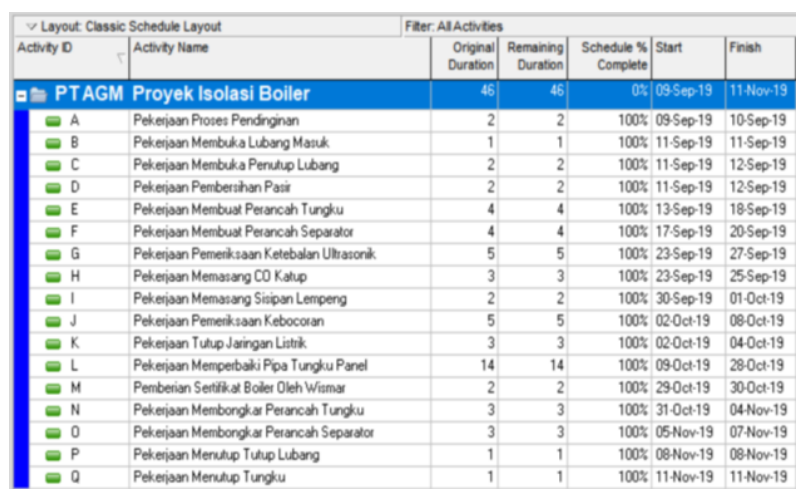

Gambar 2. Activity dan Durasi Penyelesaian Proyek

Selanjutnya terdapat hasil relationship pekerjaan atau urutan pekerjaan dengan primavera project planner P6, dapat dilihat pada Gambar 3 berikut ini : 


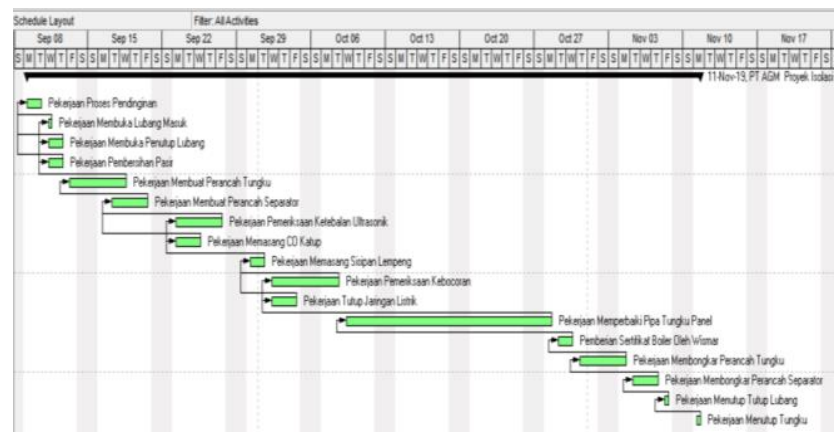

Gambar 3. Relationship Antar Aktivitas

\section{KESIMPULAN}

Dari hasil penjadwalan proyek isolasi boiler didapatkan total waktu optimal setelah pelaksanaan proyek di percepat adalah 44 hari dari durasi penyelesaian normal selama 48 hari. Jadi diperlukan percepatan 4 hari agar proyek selesai sesuai target rencana.

Biaya total optimal yang harus di keluarkan setelah pelaksanaan proyek dipercepat yaitu sebesar Rp.643.249.048 dari biaya normal sebelum percepatan sebesar Rp.642.141.700 jadi terjadi penambahan total biaya sebesar Rp.1.107.348.

\section{REFERENCES}

[1] Adhityarahman, S. (1996). Manajemen Proyek \& Konstruksi. Yogyakarta: Kanisius.

[2] Anastasia Florensia Mela. (2016). Analisis Time Cost Trade Off Untuk Mengejar Keterlambatan Pelaksanaan Proyek Studi Kasus : Pembangunan Hotel Zodiak Lampung, Pembangunan Hotel Park In By Radisson, Pembangunan Toko Mitra Hasil Sentosa Di Bandar Lampung. Skripsi. Universitas Lampung

[3] Bagus Budi Setiawan. (2012). Analisis Pertukaran Waktu Dan Biaya Dengan Metode Time Cost Trade Off (Tcto) Pada Proyek Pembangunan Gedung Di Jakarta. Jurnal Konstruksia, hlm 25-34.

[4] Berutu, Adestin Sin. (2005). Primavera Project Planner. Yogyakarta: Andi.

[5] Christianto V, Wirayana I Made. (2002). Manajemen Proyek Berbasis Internet. Jakarta: PT Elex Media Komputindo.

[6] Dennis. (1987). Manajemen Proyek. Jakarta: Erlangga.

[7] Dipohusodo, I. (1996). Manajemen Proyek Dan Konstruksi. Yogyakarta: Kanisius

[8] Fadllan. (2018). Analisis Optimasi Waktu Dan Biaya Dengan Metode Time Cost Trade Off Pada Proyek Pembangunan Kapal: Studi Kasus Pembangunan Kapal Kelas I Kenavigasian Di Galangan Kapal Batam, Kepulauan Riau. Skripsi. Institut Teknologi Sepuluh November

[9] Frederika, A. (2010). Analisis Percepatan Pelaksanaan dengan Menambah Jam Kerja Optimum pada Proyek Konstruksi. Jurnal Ilmiah Teknik Sipil, 14(2).

[10] Herjanto, E. (2003). Manajemen Produksi dan Operasi. Jakarta: Grasindo.

[11] Kusuma Doni Probo, dkk. (2015). Pengendalian Biaya Dan Waktu Pada Proyek Pembangunan Hotel Dengan Menggunakan Primavera Project Planner P6. Jurnal Matriks Teknik Sipil, hlm 766-774.

[12] Nurhayati. (2010). Manajemen Proyek. Yogyakarta: Graha Ilmu.

[13] Pastiarsa, Made. (2015). Manajemen Proyek Konstruksi Bangunan Industri. Yogyakarta: Teknosain. 